ship calls into question the $\mathrm{PhD}$ degree as a unified system of training and examination. Those responsible for the trend must decide whether there is a role for the studentship, and if the answer is positive, they should endeavour to fight for a better grant for the PhD student, and restrict $\mathrm{PhD}$ research assistantships to exceptional cases. If the answer is paid employment of all PhD students, those responsible should remember that it is their responsibility to promote individuality, innovation and a sense of independence, qualities which have undoubtedly been part of the reason for their own elevated position. If the current situation continues, the institution of the PhD student can only be undermined and possibly lost.

A.J. Greenfield

81 Wellesley Court,

London W9 1R1, UK

SIR-With reference to Beverley Halstead's comments on $\mathrm{PhD}$ training, the thinking at South African universities is currently in a 'reform' phase. A common view among academics is that the thesis should still weigh in at a certain level (it must not be too light) but that it is desirable that at least some of the material should have appeared in print before submission of the thesis. A reason often given is that papers published in refereed journals represent a sort of antidote to overcritical examiners. What has recently stimulated supervisors to encourage MSc and $\mathrm{PhD}$ students to publish is, however, the fact that the annual government subsidy now received by each university is based partly on the publication output (in high-quality journals) of the institution concerned. Some of this money frequently finds its way into the supervisor's research grant.

Department of Zoology

University of the Witwatersrand,

Johannesburg, South Africa

SIR-The commentary by Beverley Halstead emphasizes the importance of publishing parts of the thesis before the $\mathrm{PhD}$ is awarded, a view I fully support. However, the space permitted for a publication often varies between journals, the most contested journals generally requiring the author to be particularly brief and concise. As a consequence, a published paper may not contain the wider discussion of a subject as is expected from a thesis, and hence the two forms of written work should ideally complement each other. In this respect, I believe that the British $\mathrm{PhD}$ is more than a collection of original (published) papers and represents an important contribution to the scientific literature in its own right. Halstead writes: "During the course of my PhD I published a paper - it was far more exciting for me to do this than write a thesis". To this I would like to reply: during the course of my PhD I published a paper - and as I was restricted to keeping the length of the paper to the absolute minimum I particularly enjoyed writing the corresponding chapter of my thesis. The paper was published, but the thesis gives a fuller account of the scientific findings and their relevance.

Is it the relative inaccessibility of the British thesis that needs a change? At present, only one mandatory copy is deposited in the departmental and in the main library of the university where the degree is taken (in my case at Reading in England). The printing and circulation of a large number of copies, traditionally the case in West Germany, would improve this situation.

Department of Cell Biology,

Fraunhofer-Institute, ITA,

Nikolai-Fuchs-Str. 1 ,

3000 Hannover 61, FRG

\section{Turin Shroud}

Sir-Following my letter of 11 June 1987 (Nature 327, 456; 1987), I am now able to provide an outline of the procedures that have been finally agreed for the radiocarbon dating of the Shroud of Turin. Of the seven original offers to undertake the dating of the Shroud, three have been accepted by Cardinal Ballestrero, Archbishop of Turin and Pontifical Custodian of the Shroud. The radiocarbon laboratories concerned are at the University of Arizona, the University of Oxford and the Federal Institute of Technology in Zurich, and each has now agreed to proceed with the project.

Each laboratory will be provided with a sample from the shroud, together with two known-age control samples, one of which will have been independently dated by conventional radiocarbon dating. The shroud samples will be taken from a single site on the main body of the shroud away from any patches or charred areas. In order to ensure that ample carbon for dating survives after pretreatment, the weight of each cloth sample (that is, shroud and controls) will be $40 \mathrm{mg}$. All the samples will be given to the laboratories as whole pieces of cloth without being unravelled or shredded. A blind test procedure will be adopted in that the three samples given to each laboratory will be labelled 1,2 and 3 and the laboratories will not be told which sample comes from the shroud. Even if the samples were shredded, it would still be possible for a laboratory to distinguish the shroud sample from the others. It is therefore accepted that the blind test depends ultimately on the good faith of the laboratories.

The removal of the samples from the shroud will be undertaken under the supervision of a qualified textile expert. These samples will be weighed, wrapped in aluminium foil and sealed in numbered stainless steel containers. The control samples will be similarly treated. All these operations will be watched over and certified by Cardinal Ballestrero in collaboration with myself. After they have been packaged, we will immediately hand over three samples (shroud and two controls) to representatives of each of the three radiocarbon dating laboratories who will be in Turin for this purpose. In addition, all stages will be fully documented by video film and photography.

On completion of their measurements, the laboratories will send their data for the three samples to both myself at the British Museum and to the Institute of Metrology "G. Colonnetti" in Turin for preliminary statistical analysis. The laboratories have agreed not to discuss their results with each other until after they have deposited their data for statistical analysis. A final discussion of the measurement data will be made at a subsequent meeting in Turin between representatives of these two institutions and representatives of the three laboratories at which the identity of the three samples will be revealed. The results as finalized at this meeting will form a basis for both a scientific paper and for communication to the public. The timetable for the operations has not yet been fully established but it is hoped that a radiocarbon date for the Shroud of Turin will be released by the end of 1988 .

Research Laboratory,

M. S. TITE

British Museum,

London WCIB 3DG,

UK

\section{AIDS and HIV}

SIR-In Gregorio Weber's letter (Nature 330, 690; 1987) he says: "The prolonged absence of symptoms in a large majority of those that have contact with the [AIDS] virus is already indicative that in many probably most - of them the disease will never develop."

In fact, the San Francisco AIDS Research Study (director Paul O'Malley) has published findings that after seven years, 36 per cent of those infected with HIV (human immunodeficiency virus) have developed AIDS and another 38 per cent have developed AIDS-related complex. These results were released at the Third International Conference on AIDS in Washington in June 1987.

It is true that early in the epidemic health officials thought (or hoped) that only 10 per cent of those infected would manifest this illness. Time has shown that this is not the case.

DAIR Foundation, Inc.

Donald J. Gorman 2336 Market Street, Suite 33,

San Francisco,

California 94114, USA 